\title{
DEMOCRATIZAÇÃO DA LITERATURA NA EDUCAÇÃO BÁSICA: EXPERIÊNCIAS NO SUBPROJETOO DE PORTUGUÊS E LITERATURAS DO PIBID (2018-2020) NA UFRJ
}

\author{
Alessandra Fontes Carvalho da Rocha ${ }^{1}$ \\ Diego Domingues ${ }^{2}$ \\ Luiz Guilherme Ribeiro Barbosa ${ }^{3}$ \\ Marcos Scheffel ${ }^{4}$
}

\begin{abstract}
Resumo: A partir da articulação entre educação básica e ensino superior, apresentamos, neste artigo, alguns trabalhos desenvolvidos entre setembro de 2018 e dezembro de 2019 no Programa de Iniciação à Docência (Pibid) na Universidade Federal do Rio de Janeiro (UFRJ). Pretendemos falar sobre dois dos projetos que tiveram lugar em dois núcleos do Pibid: i) Mobilivro, que aborda a formação de comunidades de leitores na escola; e ii) A poesia ao meu redor: $o$ diálogo entre a produção poética da baixada fluminense e aulas do sexto ano, que desenvolveu o letramento literário dos alunos, partindo do diálogo proposto entre poetas do cânone brasileiro e autores contemporâneos moradores da mesma região na qual a escola está localizada. Antes disso, consideramos alguns aspectos teóricos sobre o letramento literário e a educação literária que sempre nortearam nossas ações em tais projetos e os saberes necessários para a prática docente.
\end{abstract}

Palavras-Chave: formação de professores. Letramento literário. Saberes docentes. Comunidade de leitores.

\section{DÉMOCRATISATION DE LA LITTÉRATURE EN ÉDUCATION DE BASE: EXPÉRIENCES DANS LE SOUS-PROJET PORTUGAIS ET LITTÉRATURES DU PIBID (2018-2020) À L'UFRJ}

Résumé: À partir de l'articulation entre l'éducation de base et l'enseignement supérieur, nous présentons, dans cet article, quelques travaux développés entre septembre 2018 et décembre 2019 dans le cadre du Programa de Iniciação à Docência (Pibid) dans l' Universidade Federal do Rio de Janeiro

\footnotetext{
${ }^{1}$ Professora de Didática Especial e Prática de Ensino de Português-Literaturas da Faculdade de Educação da UFRJ. Coordenadora de Área do PIBID de Português - CAPES.

2 Professor de Português na Rede Municipal de Duque de Caxias/RJ. Professor supervisor do Pibid de Português na Escola Municipal Nísia Vilela Fernandes - CAPES.

${ }^{3}$ Professor de Português e Literaturas de Língua Portuguesa no Colégio Pedro II. Professor supervisor do Pibid de Português no Colégio Pedro II - CAPES.

${ }^{4}$ Professor de Didática Especial e Prática de Ensino de Português-Literaturas da Faculdade de Educação da UFRJ. Coordenadora de Área do PIBID de Português - CAPES.
} 
(UFRJ). Nous avons l'intention de parler de deux des projets qui se sont déroulés en deux groupes du Pibid: i) Mobilivro qui aborde la formation de communautés de lecteurs à l'école; et ii) $A$ poesia ao meu redor: o diálogo entre a produção poética da baixada fluminense e aulas do sexto ano qui a développé le lettrement littéraire des élèves, à partir du dialogue proposé entre les poètes du canon brésilien et les auteurs contemporains vivant dans la même région où se situe l'école. Avant cela, nous avons considéré certains aspects théoriques du lettrement littéraire et de l'éducation littéraire qui ont toujours guidé nos actions dans les projets et les connaissances nécessaires à la pratique de l'enseignement.

Mots-clés: formations des professeurs. Lettrement littéraire. Les savoirs du professeur. Communauté de lecteurs.

\section{Formar leitores em um curso de Letras?}

Entre setembro de 2018 e dezembro de 2019, o subprojeto de Português e Literaturas do Programa de Iniciação à Docência (Pibid) na Universidade Federal do Rio de Janeiro (UFRJ) teve atividades em três escolas públicas do Estado do Rio de Janeiro. Duas delas localizadas em bairros suburbanos da Zona Norte da capital do Estado - uma Federal, o Colégio Pedro II, no campus Engenho Novo II; outra, a Escola Municipal Dilermando Cruz, no bairro de Bonsucesso - e uma localizada no município de Duque de Caxias, a Escola Municipal Nísia Vilela Fernandes.

A parceria estabelecida com estas escolas para realização do Pibid liga-se diretamente a uma série de opções políticas no campo da formação de professores e das identidades docentes que procuramos construir em nossas licenciaturas. São escolas periféricas, de diferentes redes de ensino, com diferentes realidades, com diferente Índice de desenvolvimento da educação básica (Ideb) e com professores que vêm há anos recebendo os estagiários da UFRJ e que, por conta disso, conhecem alguns princípios que norteiam esta formação. Alguns destes princípios estão explicitados na mais recente iniciativa no campo formativo: o Complexo de Formação de Professores, que tem por objetivo:

Forjar um lugar específico de formação constituído pela interseção da UFRJ (nos termos do item anterior) com escolas de Educação Básica pública (municipais, estaduais e federais) selecionadas como escolas formadoras, 
DEMOCRATIZAÇÃO DA LITERATURA NA EDUCAÇÃO BÁSICA: EXPERIÊNCIAS NO SUBPROJETO DE PORTUGUÊS E LITERATURAS DO PIBID (2018-2020) NA UFRJ

constituindo um lócus de novo tipo, em que processos de formação sistemática de parte importante da licenciatura possam acontecer por meio de diálogos, práticas, estudos teóricos, envolvendo docentes universitários, da educação básica, estudantes das licenciaturas e, mais amplamente, a comunidade escolar (COMPLEXO DE FORMAÇÃO DE PROFESSORES, 2020).

Este "lugar" do Complexo de Formação de Professores não é físico, mas sim regido por princípios, como o estabelecimento de relações horizontais com as escolas parceiras, reconhecendo a escola como espaço construtor de saberes ligados à docência que são essenciais para cursos que têm por escopo a formação de professores para atuarem na educação básica, como são ou deveriam ser as licenciaturas. De certa forma, esta relação mais horizontal com a educação básica e com uma cultura profissional é um dos principais escopos do Pibid, que tem como um dos seus objetivos:

Inserir os licenciandos no cotidiano de escolas da rede pública de educação, proporcionando-lhes oportunidades de criação e participação em experiências metodológicas, tecnológicas e práticas docentes de caráter inovador e interdisciplinar que busquem a superação de problemas identificados no processo de ensino-aprendizagem (PIBID).

Em 2018, ocorreu a última edição do Pibid, na qual houve uma mudança significativa nos critérios de seleção dos alunos que participariam do programa. Os candidatos deveriam ter cursado até metade do curso, já que o tempo dedicado ao programa poderia aproveitado para complementar a carga horária da Prática de Ensino. ${ }^{5}$ Em termos práticos, isto nos fez privilegiar alunos de períodos iniciais do curso de Letras de Português e Literaturas e das demais licenciaturas duplas (a UFRJ tem onze habilitações na modalidade dupla), pois, após atingir a metade do curso, havia uma orientação para pedir o desligamento dos bolsistas do programa. Pode-se dizer que tínhamos alunos

\footnotetext{
${ }^{5}$ Face ao caráter tecnicista deste programa, que prevê ensinar como se aplicar a Base Nacional Comum Curricular (BNCC), a UFRJ não aderiu ao Programa de Residência Pedagógica. Decisão tomada pelo colegiado da Faculdade de Educação após amplo debate.
} 
com uma experiência incipiente do ensino superior e que traziam ainda muito presente sua vivência como alunos da educação básica.

Quando surgiu a publicação da chamada para o programa no grupo da Faculdade de Letras no Facebook, vi uma oportunidade de conhecer esse mundo e resolvi tentar uma vaga. Poderia descobrir a sala de aula não mais como aluna, mas agora como professora. No começo foi estranho, pois estamos acostumados desde a infância a nos comportar e a conceber uma aula como aluno. Por conseguinte, precisei redirecionar o meu olhar, o que não foi imediato; nos primeiros contatos com os supervisores e suas turmas insistia em observar de uma mesma ótica, a do aprendizado. É inegável que parte dessa ótica recai na nova, já que precisamos aprender a lidar com a sala de aula; mas o aprendizado não se concentra mais no conteúdo propriamente dito, e sim de conquistar novas formas de repassar aquele conteúdo para o aluno, de uma maneira satisfatória tanto para eles como para nós mesmos (Cristiane Soeiro Cunha Gomes, Colégio Pedro II) ${ }^{6}$.

A maioria desses licenciandos, oriundos de escolas públicas, teve uma relação frágil ou até mesmo nula com a literatura na escola, como se observa neste outro relato:

Ninguém deveria sair da escola sem conhecer o Deadpool [referência a Rubem Fonseca]. Eu saí, infelizmente. Conheci ele no Pibid. E nada mais justo do que apresentar à escola o autor que se tornou meu favorito e que conheci nela mesma. Me sinto como retribuindo à escola por ter transformado minha relação com a literatura. Porque se hoje eu passeio pela literatura, é muito por causa daquela aula do Luiz Guilherme [supervisor do Pibid] sobre $O$ Seminarista [romance de Rubem Fonseca que estava sendo lido]. Porque depois dessa aula e de conhecer a escrita desse autor, a literatura mergulhou na minha vida, e eu nela. Se antes eu não andava de mãos dadas com a literatura, hoje eu não solto as mãos dela. Passeio todos os

\footnotetext{
${ }^{6}$ Os relatos aqui citados foram cedidos pelos licenciandos ao firmarem compromisso de bolsistas e voluntários do programa. Citamos o nome completo do bolsista/voluntário e a escola onde atuou no programa. A ideia destes diários de bordo foi fazer um registro durante o percurso do programa para acompanhar como se dava a construção das identidades docentes destes licenciandos.
} 
DEMOCRATIZAÇẦO DA LITERATURA NA EDUCAÇĀO BÁSICA: EXPERIÊNCIAS NO SUBPROJETO DE PORTUGUÊS E LITERATURAS DO PIBID (2018-2020) NA UFRJ

Estes mesmos licenciandos agora se deparavam com um curso que tem no seu quadro de professores pesquisadores de ponta dos estudos literários, que representam uma certa tradição letrada de um país periférico de poucos leitores literários, como apontam várias pesquisas sobre a leitura no Brasil. Na quarta edição da pesquisa Retratos da leitura no Brasil, em 2015, por exemplo, com uma amostra de 5 mil entrevistados, os dados apontam que 54\% dos pesquisados não leem livros de literatura por vontade própria, como contos, romances ou poemas. Sobre a média de livros lidos nos últimos três meses durante a realização da pesquisa entre todos os entrevistados, apenas 0,72\% realizam leitura de literatura por vontade própria e 0,31\% leem livros de literatura indicados pela escola.

Temos a impressão de que nossos cursos de Letras - principalmente aqueles mais prestigiados em termos de pesquisa acadêmica - têm uma dificuldade enorme em lidar com licenciandos com este perfil e que, por conta disto, adotam uma postura de "manter o sarrafo alto". Postura que faz alguns alunos passarem o sarrafo, outros a se chocharem nele, outros a passarem por baixo do obstáculo e outros a simplesmente desistirem do salto. Esta mesma postura tem consequências graves quando replicada na educação básica, pois valoriza uma concepção da literatura como algo para poucos, para saltadores altamente habilitados e desvaloriza os processos contínuos de formação de leitores.

Eu tinha 18 anos e desisti [do curso de Letras] não foi por acaso. Via neste curso uma perspectiva reflexiva e filosófica que me punha à margem e sempre a questionar sobre o meu lugar de pertencimento. Por isso fui parar nas exatas [cursou Arquitetura]. E dez anos depois aqui estou. Como são as coisas né? (Guilherme Nascimento, Escola Municipal Dilermando Cruz)

Cientes de tais especificidades, enfocamos nos núcleos de nosso subprojeto do Pibid aspectos ligados ao letramento literário e à educação literária destes licenciandos, que fizeram registros em forma de diário sobre as experiências que tiveram ao longo do programa nas atividades e projetos 
desenvolvidos nas escolas parceiras. Pretendemos aqui falar de dois destes projetos: Mobilivro e A poesia ao meu redor: o diálogo entre a produção poética da baixada fluminense e aulas do sexto ano, que tiveram lugar em dois núcleos do Pibid. Antes disso, queremos considerar alguns aspectos teóricos sobre o letramento literário e sobre a educação literária que sempre nortearam nossas ações em tais projetos.

\section{Letramento literário, educação literária e saberes necessários para prática docente}

Em artigo publicado na Revista Bakhtiniana, em 2014, João Wanderley Geraldi demonstra desconforto com aquilo que ele denominou de "gaseificação" do termo letramento, que teria se espalhado em reflexões teóricas do campo da linguística e em especial em documentos oficiais e políticas de formação de leitores. Segundo o autor, o enfoque nos letramentos trouxe distorções para o campo educacional brasileiro quanto aos critérios de seleção de gêneros do discurso a serem adotados em sala de aula - isto em documentos oficiais e livros didáticos - privilegiando-se muitas vezes gêneros da práxis social que poderiam ser aprendidos/compreendidos na própria vida e deixando de lado outros que, em um país desigual como o nosso, muitos só têm acesso na escola, caso das artes e da literatura. Logo:

Não cabem à escola de ensino básico todos os diferentes
letramentos, no sentido que estamos atribuindo a
"diferente" neste item. Cabe reconhecer a multiplicidade e
escolher alguns gêneros - e, portanto, algumas esferas de
comunicação - como fundamentais. Entre estes,
seguramente se encontram os campos da literatura e das
artes, pois o acesso a tais bens culturais, patrimônio da
humanidade, deve ser privilegiado pela escola (GERALDI,
2014, p. 31).

A reflexão crítica de João Wanderley Geraldi, nome marcante nas discussões sobre a leitura e a escrita em sala de aula desde os anos 1980, nos parece pertinente. Prova disso é a Base Nacional Comum Curricular (BNCC), que privilegia "os diferentes letramentos, os letramentos digitais, os letramentos multissemióticos etc.", enquanto deixa a literatura em segundo 
DEMOCRATIZAÇÂOO DA LITERATURA NA EDUCAÇĀO BÁSICA: EXPERIÊNCIAS NO SUBPROJETO DE PORTUGUÊS E LITERATURAS DO PIBID (2018-2020) NA UFRJ

plano, repetindo, em termos metodológicos, a velha fórmula de leitura literária como fruição. Vejamos um longo excerto do documento que é praticamente uma confissão do papel marginal da literatura no ensino escolar segundo as Bases:

As práticas de linguagem contemporâneas não só envolvem novos gêneros e textos cada vez mais multissemióticos e multimidiáticos, como também novas formas de produzir, de configurar, de disponibilizar, de replicar e de interagir. As novas ferramentas de edição de textos, áudios, fotos, vídeos tornam acessíveis a qualquer um a produção e disponibilização de textos multissemióticos nas redes sociais e outros ambientes da Web. Não só é possível acessar conteúdos variados em diferentes mídias, como também produzir e publicar fotos, vídeos diversos, podcasts, infográficos, enciclopédias colaborativas, revistas e livros digitais etc. Depois de ler um livro de literatura ou assistir a um filme, pode-se postar comentários em redes sociais específicas, seguir diretores, autores, escritores, acompanhar de perto seu trabalho; podemos produzir playlists, vlogs, vídeos-minuto, escrever fanfics, produzir e-zines, nos tornar um booktuber, dentre outras muitas possibilidades. Em tese, a Web é democrática: todos podem acessá-la e alimentá-la continuamente. Mas se esse espaço é livre e bastante familiar para crianças, adolescentes e jovens de hoje, porque a escola teria que, de alguma forma, considerá-lo?" (BNCC - Linguagens, Ensino Fundamental, 2017, p. 64).

Há um tom entusiasmado em relação às "práticas de linguagem contemporâneas" e uma possibilidade democrática de acesso e publicação em redes sociais que desconsidera a realidade escolar brasileira onde muitas escolas sequer têm tomadas funcionando na sala de aula, quem dirá possibilidade de acesso às redes sociais por alunos e mesmo professores. Fora isso, fica bastante evidente o tom secundário que a literatura assume aqui, já que ela só é citada após um longo elogio às "novas formas de produzir" textos. Claro que é importante pensar em critérios de seleção/curadoria de textos e informações, mas mais uma vez essa responsabilidade é depositada na disciplina de língua portuguesa. Essa sobrecarga - de se trabalhar com tudo, com a quase totalidade dos gêneros - põe a literatura num lugar de quase 
esquecimento que o próprio documento pede desculpas em uma nota de rodapé na página seguinte:

O espaço maior nesse trecho introdutório destinado aos novos letramentos e à cultura digital é devido tão somente ao fato de que sua articulação ao currículo é mais recente e ainda pouco usual, ao contrário da consideração dos letramentos da letra já consolidados. Os quadros de habilidades mais adiante atestam ainda a primazia da escrita e do oral (BNCC - Linguagens, Ensino Fundamental, 2017, p. 64).

Não há como resolver este erro metodológico e de escolhas políticas com uma nota de rodapé. Ao colocar no centro "as práticas de linguagem contemporâneas", os documentos oficiais fundam uma política que irá influenciar a confecção de livros didáticos, cursos oferecidos por secretarias, programas como o Residência Pedagógica, que valorizam um caráter de aplicação dos documentos, em concursos para o magistério, em currículos de cursos de licenciatura e em práticas de sala de aula. Isto pode se configurar em um verdadeiro sumiço da literatura muito mais grave do que aquele temido por Leyla-Perrone Moysés, quando da discussão dos Parâmetros Curriculares Nacionais: “Todos esses documentos evidenciam um fato: a literatura é uma disciplina ameaçada. As diretrizes do MEC não são a causa dessa ameaça: são sintoma" (PERRONE-MOISÉS 1996, p. 27).

Enquanto profissionais que atuam na educação básica, em diferentes papéis, temos que tencionar e refletir sobre o que significam determinados direcionamentos e procurar alternativas para que leituras críticas e reflexivas de tais documentos possam conduzir a práticas que viabilizem o acesso democrático à arte, à literatura. Esses são saberes docentes que estão em jogo na formação inicial e continuada de professores. Antes do ensinar, propriamente dito, o docente faz escolhas - principalmente políticas - que orientam toda sua prática. No campo do ensino de Português e Literaturas, tais escolhas são cruciais para tarefas que são de responsabilidade do professor. Destacamos, aqui, as que serão mais evidenciadas, posteriormente, na apresentação de dois projetos realizados durante o Pibid 2018-2020: i) a formação de uma comunidade leitora e, sobretudo, de leitores literários; ii) a 
DEMOCRATIZAÇÂOO DA LITERATURA NA EDUCAÇÃO BÁSICA: EXPERIÊNCIAS NO SUBPROJETO DE PORTUGUÊS E LITERATURAS DO PIBID (2018-2020) NA UFRJ

seleção de obras e autores a serem apresentados em sala de aula; iii) a curadoria, a seleção dos textos. Essas tarefas não são nada fáceis quando se percebe que, segundo Tardif \& Lessard (2009, p. 100), “ensinar é trabalhar num ambiente organizacional fortemente controlado, saturado de normas e regras e, ao mesmo tempo, agir em função de uma autonomia importante e necessária para a realização dos objetivos da própria escola".

Entre controle e autonomia para realização dos objetivos da escola, conforme consta na citação, está a identidade docente vinculada ao que esse sujeito sabe sobre o que é preciso para a sala de aula e suas ações com, sobre e para o outro. E é por isso que temos em todos os atos da profissão de professor um compromisso político atrelado ao trabalhado desenvolvido em sala de aula. Afinal, “[...] não se pode refletir sobre a educação sem antes, ou simultaneamente, refletir sobre essa coisa tão fundamental no viver cotidiano que é o projeto de país no qual estão inseridas nossas reflexões sobre a educação. Temos um projeto de país? [...]" (MATURANA, 1998, p. 12). Sem dúvida, para professores, essa é uma pergunta crucial antes de qualquer escolha. E, para além do questionamento, saber o nosso posicionamento diante da resposta é o que faz com que o trabalho docente contribua para atender o principal: necessidades humanas para formação humana. Nesse campo voltamos à literatura e às outras artes, pois, segundo Antonio Candido (2011), em “O direito à literatura”, a literatura é um direito básico do ser humano.

Ao mesmo tempo não podemos esquecer que nossos alunos, tanto da educação básica como do ensino superior, são, nas palavras de Nestor GarcíaCanclini, "leitores, expectadores e internautas" (2008). Linguagens que muitos deles dominam - precisando, sim, apropriar-se criticamente delas - mas será que é na leitura destes mesmos gêneros que este leitor crítico vai se formar?

\section{A formação de comunidade de leitores}

Uma das preocupações do projeto Pibid, que faz dialogarem estudantes e professores do ensino superior público com estudantes e professores da educação básica, diz respeito à integração dos pibidianos na comunidade escolar. O reconhecimento de cada graduando como professora ou professor pelos estudantes representava, para cada um deles, um desafio 
inédito na sua trajetória, e era preciso, portanto, fomentar a elaboração de identidades docentes baseadas nas experiências escolares e universitárias de cada um.

Como estamos imbuídos de um projeto de ensino de literatura voltado para a formação de leitores, resgatar a memória e a identidade desses pibidianos como leitores, apresentá-la aos alunos da escola e, a partir disso, elaborar um projeto de mediação de leitura que inserisse esses recém-chegados na rotina escolar foi uma estratégia importante durante as atividades do Pibid no Colégio Pedro II do Engenho Novo.

Assim, chegamos à compreensão de que as relações afetivas entre os livros de ficção e seus leitores deveria conduzir a integração dos pibidianos nas turmas em que atuaram e, por isso, um dos projetos de mediação de leitura desenvolvidos esteve baseado na premissa de que produzir cultura literária na escola significa produzir, ao mesmo tempo, cultura democrática.

O trabalho de integração requereu a triangulação entre estudantes, professor e estagiários, o que implica refazer os lugares de autoria na sala de aula. Depois de uma coparticipação numa aula em que se apresentou como leitora, uma pibidiana relatou a diferença observada:

Eu gostei como a turma se engajou com a minha participação e eu notei que eles estavam ainda mais engajados quando o [professor] Luiz falava. Acho que a nossa interação fez com que o ambiente de aprendizagem ficasse mais dinâmico - assim, também acredito que quando eu interferia na performance dele, havia uma interação maior dos alunos. Acho que isso se dá pela quebra do monólogo. O ideal, acredito eu, é que as aulas fossem sempre tão dinâmicas e isso seria facilmente pela interação de todos eles na discussão. Mas a interação deles ainda é muito tímida, ao meu ver, porque a vida inteira lhes foi dito que o momento da aula era o momento apenas de escutar. A discussão, o questionamento, a intervenção foram desde sempre deixados de lado. Sendo algo tão internalizado, é realmente difícil a quebra desse paradigma não importando o quão encorajador o professor possa ser. Falo, ao menos, da minha experiência de aluna, que foi sempre tão engajada em aprender coisas novas, tão apaixonada pelos estudos e discussões (Cristiane Soeiro Cunha Gomes, Colégio Pedro II). 
DEMOCRATIZAÇÂOO DA LITERATURA NA EDUCAÇĀO BÁSICA: EXPERIÊNCIAS NO SUBPROJETO DE PORTUGUÊS E LITERATURAS DO PIBID (2018-2020) NA UFRJ

Relacionar as primeiras experiências docentes com a memória escolar parece fundamental para a invenção como professora, pois se trata de momento de reconhecimento de si na história da educação, ou na história de cada um com a educação. O marcado discurso de crise moral da educação contemporânea, disseminado como senso comum, encontra alguma refutação na leitura, por essa pibidiana, de que a sala de aula fomenta a cultura democrática, numa escola que se reconhece como instituição mais coletiva e, sendo menos calcada no trabalho individual de professores e de estudantes, menos heroica - já que o professor-herói costuma ser figura solitária no seu contexto adverso. É decisivo, sob essa perspectiva, que os saberes presentes na sala de aula tenham o monopólio quebrado, cabendo ao professor e aos pibidianos elaborar projetos pedagógicos que fomentem a aprendizagem daqueles coletivos especificamente, ou seja, de cada turma. Aqui, espírito crítico não se transmite a partir de um discurso positivo que o propagandeie, mas pode se constituir na convivência entre os atores de uma sala de aula, a exemplo do que narra a mesma pibidiana acerca da avaliação de sua coparticipação em aula:

Apesar de eu e Luiz termos vistos minha participação como satisfatória, ambos concordamos no que ele apontou: eu, quando estava falando da questão indígena, fazia uma separação muito marcada na minha fala entre "nós" e "os indígenas". Ele não explicou a fundo o problema a que isto se relaciona, mas acredito que são relativamente óbvios e numerosos. Por exemplo, fazer uma oposição "nós" e "os indígenas" é excluir os indígenas desse "nós", é os alienar, os fazer alheios, estrangeiros; é colocá-los como “o outro", é jogá-los em um não-lugar. É discriminatório, é excludente e vai contra a própria questão que eu estava respondendo, sobre a obtenção de direitos e assim, igualdade, na nossa própria Constituição. Assim, eu propus a ele que poderíamos voltar nesse ponto e nessa questão com os alunos na próxima aula (e problematizar um pouco mais isso). Ele concordou muito com a ideia. $\mathrm{O}$ que é mais interessante nessa reanálise, é que o aprendizado se torna ainda mais autêntico, mais real e significativo, pois é algo que eles viveram, experienciaram conosco (Cristiane Soeiro Cunha Gomes, Colégio Pedro II). 
A autenticidade reconhecida pela autora do diário nos parece resultado do trabalho de letramento, na medida em que esse processo não deve ser concebido, na educação básica, apenas em caráter instrumental, mas, sobretudo, formativo. Não se trata, nesse contexto, de ensinar a como representar os povos indígenas da América do Sul, pois o discurso crítico sobre essa matéria é plural (no campo da Antropologia há defesas diferentes sobre a adequação do emprego de termos como "índios", "indígenas", "povos da floresta", “culturas ameríndias", etc.) e, conforme afirmamos, a relação pedagógica deve prevalecer no processo de formação para o letramento e construção da identidade docente. Isso quer dizer que as condições favoráveis de aprendizagem, baseadas não apenas na infraestrutura material e simbólica das escolas, mas também nas relações pedagógicas entre aqueles que participam da comunidade escolar, devem anteceder a matéria ensinada, cujo aprendizado não está garantido fora da cultura democrática.

Foi partindo dessa concepção que um dos projetos de mediação do Pibid no Colégio Pedro II procurou formar uma comunidade de leitores a partir do engajamento da comunidade escolar na eleição de um livro de ficção a ser lido coletivamente. Baseado em experiências do tipo "One city one book" ou aplicadas a instituições de ensino, ${ }^{7}$ e em diálogo com o projeto de seleção pública de livros de ficção a serem lidos por todos os candidatos do Vestibular $\mathrm{UER}^{8}$, um coletivo de pibidianos atuantes no Colégio Pedro II elaborou o projeto Mobilivro. A concepção e a execução do projeto se deu de forma coletiva entre professor e pibidianos, e foram produzidos oito documentos: plano de trabalho; logotipo do projeto; perfil na rede social Instagram; carta-convite aos grupos da comunidade escolar que trabalham com a formação de leitores;

\footnotetext{
7 Algumas delas, desenvolvidas em cidades dos EUA, estão listadas no endereço eletrônico: https://en.wikipedia.org/wiki/One_City_One_Book, acessado em 25 de abril de 2020. Em relação a instituições de ensino, a leitura do projeto de livro comum desenvolvido na Universidade de Santa Bárbara foi uma referência importante, disponível no endereço: https://www.library.ucsb.edu/ucsbreads, acessado em 25 de abril de 2020.

8 "Desde 2017, o Vestibular da UERJ indica uma lista de livros de literatura, utilizados nas provas de Linguagem, no exame de qualificação, de Redação e de Língua Portuguesa e Literaturas, no exame discursivo. O resgate dessa lista de livros de literatura facilita tanto os candidatos, por aumentar a previsibilidade das provas, quanto as bancas de correção, por aumentar a qualidade do desempenho dos candidatos. Esse resgate destaca também a importância da literatura para a construção interdisciplinar do conhecimento." Disponível em: https://www.uerj.br/vestibular, acessado em 25 de abril de 2020.
} 
DEMOCRATIZAÇÂOO DA LITERATURA NA EDUCAÇĀO BÁSICA: EXPERIÊNCIAS NO SUBPROJETO DE PORTUGUÊS E LITERATURAS DO PIBID (2018-2020) NA UFRJ

formulário eletrônico de votação dos livros de ficção indicados pelos grupos de formação de leitores; vídeo-resenhas dos livros candidatos; análise do processo de votação nos livros candidatos; relatos da roda de leitura do livro vencedor. Ao avaliar os limites e a contribuição desse projeto para a comunidade escolar, o relato que elaboramos analisando o processo de votação parece revelador:

Dos seis comentários enviados pelos votantes, um foi bastante significativo. Uma estudante do oitavo ano do ensino fundamental parabenizou o projeto pela qualidade dos livros candidatos e concluiu com uma frase cujo sentido extrapola os objetivos específicos dessa iniciativa: "Obrigado por sempre nos oferecerem a oportunidade de participar de projetos incríveis!!!” A indeterminação no endereçamento do discurso insere o projeto Mobilivro num contexto de pluralidade de projetos pedagógicos existentes na escola. Esse comentário revela como um projeto pedagógico participa da produção cultural escolar fomentando possibilidades de formação, a serem oferecidas de acordo com o interesse dos estudantes. Assim, a análise quantitativa do engajamento dos estudantes pode ser revista sob uma perspectiva qualitativa, que se interesse por analisar o vínculo pedagógico que o projeto produziu ao longo do ano letivo com estudantes singulares. E o momento pós-votação de leitura do livro escolhido é oportuno para começar essa análise.

Foram recebidos 66 votos, dos quais 33 de alunos do ensino médio, oito de alunos do ensino fundamental, 22 de professora, professor, e demais profissionais da instituição, e 3 de mãe, pai ou responsável. Reconhecendo o baixo índice de engajamento dos estudantes numa iniciativa que considerou as redes sociais como principal estratégia de comunicação, a análise desenvolvida destacou a importância do contexto de iniciativas plurais de formação para a leitura. Foi a aliança com as iniciativas já existentes o principal fator de engajamento, demonstrando como a convivência rotineira entre leitores é determinante para a formação de uma comunidade.

Além disso, avaliou-se que a turma, por ser um coletivo já constituído na rotina escolar, deve ser considerada a célula básica de uma comunidade de leitores num projeto dessa natureza, e o trabalho de seleção de livros de ficção 
a ser lido durante o ano pode ser realizado em diálogo com o currículo das aulas de Português e Literaturas. Nesse sentido, um dos principais objetivos do projeto Mobilivro foi alcançado: a contribuição do Pibid para a escola como legado curricular, compreendendo o trabalho de formação de leitores como direito dos estudantes e, por isso, articulado à formação para o letramento baseada na cultura democrática.

\section{A mediação entre o cânone e o contemporâneo}

Partindo, então, dos saberes necessários para a prática docente anteriormente mencionados e, também, das escolhas provenientes da reflexão dos professores sobre o meio no qual estão inseridos, esta seção irá comentar sobre o projeto envolvendo literatura em uma turma de sexto ano da Escola Municipal Nísia Vilela Fernandes (Duque de Caxias/RJ). Tal projeto, que contou com a participação de dois bolsistas que cursavam os primeiros anos da Graduação em Letras, teve como principal objetivo desenvolver o letramento literário dos alunos, partindo do diálogo proposto entre poetas do cânone brasileiro e autores contemporâneos moradores da mesma região na qual a escola está localizada.

Pensar o desenvolvimento de um projeto que tem a literatura tanto como ponto de partida, quanto ponto de chegada, é tarefa que demanda levar em consideração não somente quais gêneros literários serão explorados ou quais os autores escolhidos, mas, também, que concepções políticas sobre ensino estão guiando essas práticas, que visões de mundo o professor estará mobilizando ao propor determinadas atividades e, principalmente, quais expectativas de alunos leitores essas práticas pedagógicas estão (des)legitimando.

É particularmente importante este último ponto, pois o processo de ensino e aprendizagem, se verdadeiramente dialógico, não pode se furtar de partir dos referenciais discentes, de suas expectativas e repertórios para que o trabalho em sala de aula seja produtivo e não atenda meramente a uma demanda profissional ou pessoal do docente. Em outras palavras, as principais motivações para aulas envolvendo textos literários não deveria ser somente a exigência de determinado currículo ou o gosto particular do professor. 
DEMOCRATIZAÇẪO DA LITERATURA NA EDUCAÇÃO BÁSICA: EXPERIÊNCIAS NO SUBPROJETO DE PORTUGUÊS E LITERATURAS DO PIBID (2018-2020) NA UFRJ

Ao pensar sobre o dever que tenho, como professor, de respeitar a dignidade do educando, sua autonomia, sua identidade em processo, devo pensar também, como já salientei, em como ter uma prática educativa em que aquele respeito, que sei dever ter ao educando, se realize em lugar de ser negado. Isso exige de mim uma reflexão crítica permanente sobre minha prática através da qual vou fazendo a avaliação do meu próprio fazer com os educandos. [...] O trabalho do professor é o trabalho do professor com os alunos e não do professor consigo mesmo (FREIRE, 2011, [1996], p. 51).

Jamais querendo menosprezar o saber dos alunos, a seleção de textos precisa ter um determinado rigor pedagógico, evitando justificativas subjetivas que se apoiam majoritariamente no caráter estético do texto. Sobre esse aspecto, Vicent Jouve (2012) comenta sobre o risco em se ter o prazer estético como eixo para o ensino de literatura, para ele "ensinar normativamente o prazer estético é não apenas impossível (e, por sinal, eticamente discutível), como também inútil" (p. 134). E, mais adiante, o autor diz:

No quadro do ensino, temos todo o direito de dispensar o critério de satisfação, fazendo valer que as obras literárias não existem unicamente como realidades estéticas. Elas são também objetos da linguagem que - pelo fato de exprimirem uma cultura, um pensamento e uma relação com o mundo- merecem que nos interessemos por elas. Se a dimensão estética tiver sido levada em conta, não terá sido por si mesma, mas por aquilo que ela significa e representa (JOUVE, 2012, p. 135).

Ainda comentando sobre a seleção de obras e autores a serem apresentados em sala de aula e refletindo sobre como essa curadoria de textos pode ser realizada, cabe também levarmos em consideração a relação, nem sempre isenta de atritos, entre a produção cultural socialmente prestigiada, as culturas locais e as culturas escolares.

Quando estamos falando de turmas de escolas localizadas em espaços periféricos da cidade, como é o caso da escola em questão, é importante lembrar a incompatibilidade que, muitas vezes, ocorre entre o que a sociedade considera como cultura digna de ser avaliada e consumida e o que é 
considerado algo menor, subalterno, pouco digno de nota. Mediando essas manifestações aparentemente antagônicas, a escola ocupa lugar central enquanto espaço que tem como um dos principais objetivos proporcionar o diálogo entre diferentes modos de manifestação cultural ${ }^{9}$.

Não bastaria, então, apresentar textos literários consagrados, como se o fato de terem sido, em um determinado momento histórico, elevados ao patamar de cânone, desobrigasse o professor de justificar a importância dessas obras. O peso histórico, bem como as qualidades estéticas, sobre a qual já comentamos, podem não ter nenhuma relevância para os alunos, ainda mais para aqueles sem o hábito de leitura literária.

Nesse momento de primeiros contatos entre a turma e literatura é que se torna ainda mais importante estabelecer a relação entre produções culturais/artísticas reconhecidas pelos alunos e obras mais tradicionais, possivelmente ausentes de seu cotidiano. Para tal ponto, as reflexões de Roxane Rojo são bastante apropriadas, já que para autora:

Cabe à escola potencializar o diálogo multicultural, trazendo para dentro de seus muros não somente a cultura valorizada, dominante, canônica, mas também as culturas locais e populares e a cultura de massa, para torná-las vozes de um diálogo, objetos de estudo e de crítica. Para tal, é preciso que a escola se interesse por e admita as culturas locais de alunos e professores (ROJO, 2009, p. 115).

Ainda que todos os pontos até agora mencionados sejam considerados no planejamento das práticas envolvendo textos literários, percebemos que um outro importante ponto de ser analisado em todo esse processo é a própria trajetória do professor enquanto leitor.

Dificilmente um profissional de educação poderá despertar em seus alunos o interesse por obras literárias se ele próprio não for também um leitor contumaz. Esse desinteresse, por sua vez, é rapidamente percebido pelos

\footnotetext{
${ }^{9}$ Devido ao espaço do qual dispomos, não entraremos nos pormenores sobre as diversas definições de Cultura, palavra altamente polissêmica. Neste artigo, ficamos com a definição antropológica mais objetiva de cultura enquanto "conjunto de conhecimentos, costumes, crenças, padrões de comportamento, adquiridos e transmitidos socialmente, que caracterizam um grupo social." Fonte: http://michaelis.uol.com.br/ Acesso em 25.4.2020. Para apresentação aprofundada e problematização sobre o termo, recomendamos a obra de Terry Eagleton A ideia de Cultura (2000), ed. Unesp.
} 
DEMOCRATIZAÇÂOO DA LITERATURA NA EDUCAÇĀO BÁSICA: EXPERIÊNCIAS NO SUBPROJETO DE PORTUGUÊS E LITERATURAS DO PIBID (2018-2020) NA UFRJ

alunos que, por não contarem, muitas vezes, com referências de leitores em seu ambiente familiar, acabam também rejeitando a literatura na escola.

Esse ponto da dinâmica pedagógica foi ressaltado devido às reflexões dos bolsistas sobre suas experiências enquanto alunos-leitores na educação básica. Destacamos um trecho que sintetiza bem essa influência da escola sobre o desinteresse dos alunos:

Desde muito nova, sempre fui o que chamavam de "aluna exemplar". Tirava boas notas, não fazia bagunça na escola, não atrapalhava a aula etc. Apesar disso, eu, como a maior parte dos alunos de minha idade, tinha uma deficiência muitíssimo pouco ou quase nunca comentada: Não lia livros. [...] De um lado, as escolas pelas quais passei pouco motivavam os alunos a ler, não se falava sobre isso. [...] Duas escolas por onde passei indicavam livros para os alunos e alguns deles eram bons. Não eram clássicos da literatura e eu gostava bastante de alguns deles. Porém, avaliando hoje com mais afinidade o assunto, acredito que um ponto principal ajudou no meu distanciamento do hábito de ler. Os professores discutiam as leituras de forma superficial e, pouquíssimas vezes, as aulas se aprofundavam nos temas. Basicamente, os livros não tinham uma função realmente útil, mas serviam como um instrumento de avaliação e composição de nota (Raíssa Vitória de Farias Régis, Escola Municipal Nísia Vilela Fernandes).

O relato de Raíssa é bem exemplar, pois mesmo que fosse considerada "boa aluna", a literatura não fazia parte de seu cotidiano estudantil, não era um saber mobilizado e, pelo visto, sequer reconhecido como necessário para que ela pudesse ter bom rendimento escolar. Essa declaração da bolsista nos chama a atenção para um aspecto nem sempre abordado com a devida atenção: o fato de que o distanciamento dos alunos da literatura é muitas vezes provocado, direta ou indiretamente, pela própria escola.

Atividades conteudistas de pura análise gramatical em torno de um texto, pesquisa bibliográfica sobre determinado autor sem nenhuma contextualização, exercícios de interpretação com respostas únicas, desconsiderando, assim, as múltiplas interpretações de uma obra... Todas essas atividades, tão comuns no cotidiano escolar, nos levam a perceber que tão 
prejudicial quanto a ausência da literatura é sua mediação através de propostas incipientes e pouco reflexivas.

Um outro ponto que cabe mencionar sobre o relato da bolsista é que mesmo com poucas motivações escolares, isso não significa que ela desenvolveu uma relação frágil com a literatura. Ela acabou seguindo para o curso de Letras e, na primeira oportunidade que teve de lecionar em uma turma, propôs com seu colega justamente um projeto em torno de textos literários. Além do mais, Raíssa é poeta e utilizou nas aulas um de seus poemas; o que demonstra a potência da literatura mesmo diante de percursos escolares tortuosos e nem sempre estimulantes.

Decidimos dedicar a maior parte desta seção para refletirmos sobre temas que consideramos bastante significativos em todo o processo envolvendo a formação de leitores. Seguiremos, por último, para apresentação de como o projeto foi realizado.

Com o título de $A$ poesia ao meu redor: o diálogo entre a produção poética da baixada fluminense e aulas do sexto ano, começamos o projeto apresentando aos alunos, no mesmo patamar, poemas de autores canônicos e de autores contemporâneos da Baixada Fluminense. Esse primeiro movimento buscou abolir as distinções elitistas que são construídas em torno de certas produções, como se um poema fosse "marginal" ou "periférico" apenas por ter sido escrito por autores das classes populares. Essa associação bastante rasa acaba reduzindo a potência e a pluralidade de temáticas que todo poeta pode alcançar, independentemente de onde nasceu ou onde mora.

Foi realizada leitura coletiva, debate sobre os temas apresentados nos poemas, votação para que os alunos expressassem seus gostos sobre quais poemas gostaram mais. Toda essa dinâmica inicial buscou aproximá-los dos poemas, reconhecendo as qualidades literárias, mas sem reverências desnecessárias.

O projeto durou parte do segundo bimestre de 2019 e, devido ao espaço do qual dispomos, não iremos tratar de todos os detalhes. Após todo o processo de aproximação e aprofundamento em torno dos conteúdos dos poemas, da estrutura do gênero em estudo, das opiniões, críticas e dúvidas 
DEMOCRATIZAÇÃO DA LITERATURA NA EDUCAÇÃO BÁSICA: EXPERIÊNCIAS NO SUBPROJETO DE PORTUGUÊS E LITERATURAS DO PIBID (2018-2020) NA UFRJ

sobre o fazer poético; os alunos também desenvolveram suas próprias produções literárias.

Os encaminhamentos realizados no projeto buscaram, portanto, concatenar práticas de reflexão sobre a língua, leitura, e escrita, de modo que, além de explorar as obras literárias, não foram menosprezados os conteúdos tradicionais mencionados no currículo escolar.

A rigor, a dificuldade apresentada para o entendimento das obras literárias não se encontra na natureza de seus enredos, nem na profundidade psicológica de seus personagens, mas no instrumento utilizado para manifestá-las e nas equivocadas estratégias empregadas para estabelecer o contato inicial do aluno com esse material (BITTENCOURT, 2008, p. 191).

A conclusão do projeto ocorreu com a organização de um sarau, no qual os alunos que se sentiram mais à vontade leram seus poemas, que tiveram como temática "meu lugar preferido". Posteriormente todas as obras foram expostas pela escola em barbantes e folhas coloridas.

Nesse movimento, tanto de escolha do tema, quanto de exibição das produções, pudemos incentivar que os alunos valorizassem o ambiente no qual moram e convivem, destacando aspectos positivos do entorno escolar e compartilhando tais olhares com o restante da comunidade escolar, iniciativa que consideramos ter sido bastante produtiva e enriquecedora para todos os envolvidos.

\section{Considerações finais}

Os projetos desenvolvidos no Pibid, subprojeto Língua Portuguesa, e apresentados nesse artigo apontam para um trabalho com a perspectiva de que a escola é um espaço de produção de saberes sobre a docência, o ensino e a aprendizagem. Nas palavras de António Nóvoa (2017, p. 1131): “Não pode haver boa formação de professores se a profissão estiver fragilizada, enfraquecida. Mas também não pode haver uma profissão forte se a formação de professores for desvalorizada e reduzida apenas ao domínio das disciplinas a ensinar ou das 
técnicas pedagógicas. A formação de professores depende da profissão docente. E vice-versa".

Durante 18 meses, alguns licenciandos do curso de Letras da UFRJ se inseriram no ambiente escolar e participaram do cotidiano das escolas parceiras; e vivenciaram a prática docente por meio da realidade das escolas da rede pública de ensino. Eles também puderam realizar leitura coletiva, o que orientou a escrita de diários de leitura com o objetivo de relacionar o conteúdo do livro, aspectos marcantes para os(as) leitores(as) pibidianos(as) e as possíveis relações que esses(as) leitores(as) estabeleceram com o mundo e, principalmente, com as vivências nas escolas. Tais atividades consistiam no estímulo a processos autorais de gêneros orais e escritos dos(as) pibidianos(as). Paralelamente, eles também experimentaram a formação enquanto leitores acadêmicos e leitores literários; e refletiram sobre possíveis projetos pedagógicos que poderiam atender à demanda de cada escola, sempre articulando teorias e práticas sobre o ensino de língua, literatura e produção textual.

Ao final, em meio ao que vivemos como Era Digital, voltamos à reflexão sobre a possibilidade democrática de acesso e publicação em redes sociais e à valorização dos documentos oficiais em relação a práticas de linguagem contemporâneas, já mencionadas ao longo do texto, e insistimos no potencial da literatura, principalmente por entendermos que ela é "uma necessidade universal, que precisa ser satisfeita e cuja satisfação constitui um direito" (CANDIDO, 2011, p. 177) e por acreditarmos que "assim como não é possível haver equilíbrio psíquico sem sonho durante o sono, "talvez não haja equilíbrio social sem a literatura" (CANDIDO, 2011, p. 177). A partir de tal posicionamento político e pedagógico, é que buscamos o apoio nos textos literários para o fazer docente, principalmente por saber que: "A literatura confirma e nega, propõe e denuncia, apoia e combate, fornecendo a possibilidade de vivermos dialeticamente os problemas" (CANDIDO, 2011, p. 177), ações essas que, certamente, dão conta de formar leitores críticos e lúcidos. 
DEMOCRATIZAÇĀO DA LITERATURA NA EDUCAÇĀO BÁSICA: EXPERIÊNCIAS NO SUBPROJETO DE PORTUGUÊS E LITERATURAS DO PIBID (2018-2020) NA UFRJ

\section{Referências}

BITTENCOURT, T. da F. P. A língua literária e o ensino de português in Confluência: Revista do Instituto de Língua Portuguesa do Liceu Literário Português. Rio de Janeiro: Lucerna, n.33 e 34. p. 187- 201, 2008.

CANCLINI, Néstor García. Leitores, espectadores e internautas. Tradução Ana Goldberg. São Paulo: Iluminuras; Itaú Cultural, 2008.

CANDIDO, Antonio. O direito à literatura. In: Vários Escritos. 5 ed. Rio de Janeiro: Ouro sobre Azul/ São Paulo: Duas Cidades, 2011.

COMPLEXO DE FORMAÇÃO DE PROFESSORES DA UFRJ. Disponível em: https://admin.formacaodeprofessores.ufrj.br/wpcontent/uploads/2019/06/Extrato-do-Documento-Interno-do-Complexo-deForma\%C3\%A7\%C3\%A3o-de-Professores-1.pdf Consultado em: 17/04/2020

FREIRE, Paulo. Pedagogia da Autonomia: Saberes necessários à prática educativa [1996]. 1a ed. São Paulo: Paz e Terra, 2011. Versão digital.

GERALDI, João Wanderley. Bakhtiniana, 9(2); 25-34, Ago./Dez. 2014. Disponível em: $\quad$ https://revistas.pucsp.br/bakhtiniana/article/view/19443/15592 Consultado em: 17/04/2020

JOUVE, Vincent. Por que estudar literatura?São Paulo: Parábola Editorial, 2012.

MATURANA, H. Emoções e linguagem na educação e na política. Belo Horizonte: Editora UFMG, 1998.

NÓVOA, António. Firmar a posição como professor, afirmar a profissão docente. Cadernos de Pesquisa v. 47 n.166 p.1106-1133 out./dez. 2017. Disponível em: $\quad$ http://www.scielo.br/pdf/cp/v47n166/1980-5314-cp-47-166-1106.pdf Consultado em: 20/04/2020.

PERRONE-MOISÉS, Leyla. Literatura para todos. In: Literatura e sociedade. São Paulo: USP, 1996. (p.16-29) Disponível em: www.revistas.usp.br Consultado em: $17 / 04 / 2020$

PIBID - PROGRAMA DE INICIAÇÃO À DOCÊNCIA. Disponível em: https://www.capes.gov.br/educacao-basica/capespibid/pibid Consultado em: $17 / 04 / 2020$.

RETRATOS DA LEITURA NO BRASIL (2015). Disponível em: http://prolivro.org.br/home/index.php/atuacao/25-

projetos/pesquisas/3900-pesquisa-retratos-da-leitura-no-brasil-48

Consultado em: 17/04/2020 
ROJO, Roxane. Letramentos múltiplos, escola e inclusão social. São Paulo: Parábola Editorial, 2009.

TARDIF, Maurice; LESSARD, Claude. O Trabalho Docente: elementos para uma teoria da docência como profissão de interações humanas. Petrópolis, RJ: Vozes, 2009.

Recebido em 29 de abril de 2020.

Aceito em 20 de junho de 2020. 